\title{
Berberine Suppresses TPA-Induced Fibronectin Expression through the Inhibition of VEGF Secretion in Breast Cancer Cells
}

\author{
Sangmin Kim Soo-Jin Oh Jeongmin Lee Jeonghun Han Myeongjin Jeon \\ Taewoo Jung Se Kyung Lee Soo Youn Bae Jiyoung Kim Won Ho Gil \\ Seok Won Kim Jeong Eon Lee Seok Jin Nam
}

Department of Surgery, Samsung Medical Center, Sungkyunkwan University School of Medicine, Seoul, South Korea

\section{Key Words}

Berberine $\cdot \mathrm{PI}-3 \mathrm{~K} \cdot \mathrm{AKT} \cdot \mathrm{VEGF} \cdot$ Fibronectin

\begin{abstract}
Background/Aims: Berberine (BBR) is an isoquinoline alkaloid and is beneficial for the anticancer effect on a variety of human tumor cells. However, BBR's anti-angiogenesis property and its clinical potential as an inhibitor of tumor angiogenesis in breast cancer cells have not been fully elucidated. Here, we investigated the effect of BBR on TPA-induced VEGF and fibronectin (FN) as well as VEGF-induced FN in breast cancer cells. Methods: The secretion of VEGF protein was detected by ELISA. Fibronectin mRNA and protein expression was analyzed by Real-Time PCR and western blotting, respectively. The overexpressions of CA-MEK, and CA-Akt were examined by adenovirus system. Results: Our results showed that TPA, a tumor promoter, significantly increased the level of VEGF and FN expression in both MCF7 and T47D breast cancer cells. On the other hand, TPA-induced VEGF and FN expression was suppressed by LY294002, a PI-3K inhibitor. In contrast, the level of FN expression also significantly increased by constitutively active (CA)-AKT overexpression. We also found that TPA-induced VEGF and FN expression was decreased by BBR treatment. Finally, our results showed that VEGF augmented the expression of FN whereas VEGF-induced FN expression was decreased by BBR treatment. Conclusion: Taken together, we suggest that BBR may suppress TPA-induced VEGF and FN as well as VEGF-induced FN through the inhibition of the PI-3K/AKT pathway in breast cancer cells. Therefore, we suggest that BBR may be used as a candidate drug for the inhibition of angiogenesis of human breast cancer.
\end{abstract}




\section{Introduction}

Breast cancer is one of the most frequently diagnosed cancers in women worldwide and comprises a remarkably heterogeneous group of diseases [1]. The lethality of this cancer is caused by metastasis and the survival rate falls from $90 \%$ for localized breast cancer to $20 \%$ for metastatic breast cancer [2]. Cancer progression and metastasis are closely associated with epithelial-mesenchymal transition (EMT) [3]. During the EMT, epithelial proteins such as zonula occludens 1 (ZO-1) and E-cadherin, significantly are decreased while mesenchymal proteins such as vimentin and fibronectin (FN), are upregulated, facilitating the migratory phenotype [4].

Berberine (BBR) is an isoquinoline alkaloid isolated from the Chinese herb Coptis chinensis (Huanglian) [5]. BBR induces cell cycle arrest in the G1 and G2/M phases through p53-dependant up-regulation of p21 in human osteosarcoma cells [6] and induction of apoptosis in breast cancer cells [7]. In addition, BBR has an anti-metastatic effect by the modulation of MMP-1, -2 , and -9 in breast cancer and gastric cancer cells [8-10]. Here, we investigated the effect of BBR on the anti-angiogenic mechanism in breast cancer cells.

Angiogenesis is a pivotal natural process of new blood vessel formation and plays an essential role in breast cancer development and metastasis [11, 12]. Vascular endothelial growth factor (VEGF) is essential for the development of the neovasculature during tumor formation and stimulates tumor metastasis, proliferation, invasion, and endothelial cell migration $[13,14]$. The expression of VEGF directly contributes to the poor prognosis and a tendency for metastasis in solid tumors such as breast cancer [15]. The elevated expression of VEGF can be associated with shorter relapse-free survival in early-stage breast cancer patients [16]. VEGF also increases the cellular invasion of breast cancer cells in the presence of FN [17].

The stromal extracellular matrix (ECM) protein, FN is a large glycoprotein and is associated with cell differentiation, oncogenic transformation, motility and migration [18, 19]. Alterations of FN expression play a crucial role in the progression of breast cancer metastasis [20]. Aberrant FN expression have been detected in the stroma of breast cancer tissues and FN levels in breast tumor tissues are positively correlated with tumor malignancy and negatively correlated with the survival rate of breast cancer patients [21].

The aim of this study is to investigate the effect of BBR between VEGF and FN in MCF7 and T47D human breast cancer cells. We observed that the TPA-induced VEGF and FN expressions are mediated through a PI-3K/AKT-dependent mechanism in breast cancer cells. The level of FN expression was augmented by VEGF treatment. VEGF-induced FN expression was significantly decreased by BBR in breast cancer cells.

\section{Materials and Methods}

Reagents

Dulbecco's modified Eagle's medium (DMEM), RPMI1640 and the antibiotics were purchased from Life Technologies (Rockville, MD, USA). Fetal bovine serum (FBS) was purchased from Hyclone (Logan, UT, USA). Berberine was purchased from Sigma (St. Louis, MO, USA). Go6983, U0126, and LY294002 were purchased from Tocris (Ellisville, MO, USA). Tivozanib was purchased from Selleck Chemicals (Houston, TX, USA). Akt IV inhibitor, the secondary HRP-conjugated antibodies, and mouse monoclonal anti- $\beta$-actin antibody were purchased from Santa Cruz Biotechnology, Inc. (Santa Cruz, CA, USA). Rabbit monoclonal anti-fibronectin, $\mathrm{p}$-Akt, $\mathrm{p}-\mathrm{PKC}-\alpha$, and pErk1/2 antibodies were purchased from Epitomics (Burlingame, CA). MMP-1 antibody was a generous gift from Dr. Jin Ho Chung (Seoul National University, Seoul, Korea). TPA was purchased from R\&D Systems (Minneapolis, MN, USA). The ECL prime reagents were from Amersham (Buckinghamshire, UK). 
Cell culture

MCF-7 human breast cancer cells were grown in a humidified atmosphere of $95 \%$ air and $5 \% \mathrm{CO}_{2}$ at $37^{\circ} \mathrm{C}$ in DMEM supplemented with $10 \%$ FBS, $2 \mathrm{mM}$ glutamine, $100 \mathrm{IU} / \mathrm{ml}$ penicillin and $100 \mu \mathrm{g} / \mathrm{ml}$ streptomycin. T47D human breast cancer cells were grown in RPMI1640 media under the same conditions. Each cell line was maintained in culture medium supplemented without FBS for $24 \mathrm{~h}$.

Treatment with berberine and specific inhibitors

Cells were maintained in culture medium without FBS for $24 \mathrm{~h}$, and then the culture media was replaced with fresh media without FBS. Cells were pretreated with 50 or $100 \mu \mathrm{M}$ concentrations of berberine for 60 min prior to the TPA treatment and then treated with $10 \mathrm{nM}$ TPA for $24 \mathrm{~h}$. In the experiments involving specific inhibitors such as Go6983, U0126, LY294002, and AKT IV, each cell was pretreated with specific inhibitors for $30 \mathrm{~min}$ prior to treatment with TPA and then they were treated with TPA for $24 \mathrm{~h}$.

\section{Cell proliferation assay}

The cell viabilities were analyzed by Quick Cell Proliferation Assay Kit II (BioVision, Mountain View, CA) according to the manufacturer's instuctions. Briefly, MCF7 and T47D cells $\left(5 \times 10^{4} /\right.$ well) were cultured in a 96-well plate in $100 \mu \mathrm{l} /$ well of culture media in the absence or presence of the indicated dose of berberine. After incubating the cells for $24 \mathrm{~h}, 10 \mu \mathrm{l}$ WST reagent was added to each well. Viable cells were quantified photometrically at $450 \mathrm{~nm}$.

\section{Western blotting}

The cell culture media (supernatants) and cell lysates were used in the immunoblot analysis for fibronectin, MMP-1, PKC- $\alpha$, ERK, Akt, and $\beta$-actin. The proteins were boiled for 5 min in Laemmli sample buffer and then they were electrophoresed in 8\% (fibronectin) or 10\% SDS-PAGE gels, respectively. The separated proteins were transferred to PVDF membranes and the membranes were then blocked with $10 \%$ skim milk in TBS with $0.01 \%$ Tween-20 for $15 \mathrm{~min}$. The blots were incubated with anti- fibronectin, MMP-1, PKC- $\alpha$, ERK, Akt, and $\beta$-actin antibodies (1/1,000 dilution) in 1\% TBS/T buffer $(0.01 \%$ Tween 20 in TBS) at $4^{\circ} \mathrm{C}$ overnight. The blots were washed 3 times in TBS with $0.01 \%$ Tween 20 and they were subsequently incubated with anti-rabbit peroxidase-conjugated antibody (1/2,000 dilution) in TBS/T buffer. After $1 \mathrm{~h}$ incubation at room temperature (RT), the blots were washed three times and ECL plus reagents were used for development.

\section{Real-Time PCR}

The total RNA was extracted from the cells by using the TRIzol reagent (Invitrogen, Carlsbad, CA), according to the manufacturer's instructions. Isolated RNA samples were then used for RT-PCR. Samples ( $1 \mu \mathrm{g}$ of total RNA) were reverse-transcribed into cDNA in $20 \mu \mathrm{l}$ reaction volumes using a first-strand cDNA synthesis kit for RT-PCR, according to the manufacturer's instructions (MBI Fermentas, Hanover, MD, USA).

The gene expression was quantified by Real-Time PCR using a SensiMix SYBR Kit (Bioline Ltd., London, UK) and 100 ng of cDNA per reaction. The sequences of the primer sets used for this analysis are as follows: human fibronectin (forward, 5' - CCA CCC CCA TAA GGC ATA GG-3'; reverse, 5' - GTA GGG GTC AAA GCA CGA GTC ATC $-3^{\prime}$ ) and GAPDH as an internal control (forward, 5'-ATT GTT GCC ATC AAT GAC CC-3'; reverse, 5'AGT AGA GGC AGG GAT GAT GT-3'). An annealing temperature of $60^{\circ} \mathrm{C}$ was used for all of the primers. PCRs were performed in a standard 384-well plate format with an ABI 7900HT real-time PCR detection system. For data analysis, the raw threshold cycle $\left(\mathrm{C}_{T}\right)$ value was first normalized to the housekeeping gene for each sample to get the $\Delta \mathrm{C}_{T}$. The normalized $\Delta \mathrm{C}_{T}$ was then calibrated to the control cell samples to get the $\Delta \Delta \mathrm{C}_{T^{*}}$

\section{VEGF ELISA}

MCF-7 and T47D breast cancer cells were pretreated with 50 or $100 \mu \mathrm{M}$ concentrations of berberine for 60 min prior to TPA treatment and then treated with $10 \mathrm{nM}$ TPA for $24 \mathrm{~h}$. ELISA assays were performed on culture media $(400 \mu \mathrm{L})$ collected from the cells. Vehicle (DMSO) treated cells were used as a control in all of the experiments to provide baseline levels of VEGF production. Protein levels of VEGF were measured using an ELISA kit for human VEGF (Koma Biotech, Seoul, Korea), according to the manufacturer's instructions and then using a microtiter plate reader, read the plate at $450 \mathrm{~nm}$ wavelength. 
Adenovirus induction

The empty (Lac Z) and adenoviral human CA-MEK, CA-AKT, and DN-AKT cDNA were the gifts of Dr. Hyunil Ha (Korea Institute of Oriental Medicine, Daejeon, Korea). Recombinant adenovirus-expressing human CA-MEK, CA-AKT, and DN-AKT was reproduced into 293A cells.

PKC- $\alpha$ siRNA and myr-PKC- $\alpha$ transfection

PKC- $\alpha$ siRNA was purchased from Bioneer Corporation (Deajeon, Korea). Myr-PKC- $\alpha$ FLAG was a gift of Dr. Hodges (Addgene plasmid \#10807) [22]. We found that the optimal siRNA knock-down and overexpression conditions involved transfecting the MCF7 breast cancer cells at $80 \%$ confluence and the cells were maintained in DMEM with 10\% FBS; Effectene (Qiagen, Valencia, CA) was used for the transfections with PKC- $\alpha$ siRNA (25, $50 \mathrm{nM}$ or as noted) or Myr-PKC- $\alpha$ FLAG, following the protocols provided by the manufacturer. Fresh serum-free media with or without $20 \mathrm{nM}$ TPA was added $24 \mathrm{~h}$ after the $48 \mathrm{~h}$ transfection. The level of the PKC- $\alpha$ protein expression was analyzed by western blotting.

Statistical analysis

Statistical significance was determined using Student's $t$-test. Data are presented as means \pm SEM. All quoted $P$ values are two-tailed and differences were considered significant for $P$ values $<0.05$. Microsoft Excel was used for the statistical analyses.

\section{Results}

TPA augments the basal level of VEGF secretion and FN expression in the MCF7 and T47D breast cancer cells

TPA is a well known tumor promoter which acts as a potential inducer of tumor invasion and migration in various tumor cells, including breast cancer cells [23, 24]. In this study, we sought to verify the effect of TPA on the VEGF and FN protein expressions. Our results showed that the secretion of VEGF was time- and dose-dependently increased by TPA treatment in MCF7 and T47D breast cancer cells (Fig. 1A and 1B). After TPA treatment, the levels of the VEGF secretion were significantly increased to $855.2 \%$ and $1654.0 \%$ of the control level at $16 \mathrm{~h}$ and $24 \mathrm{~h}$, respectively, in MCF7 breast cancer cells (Fig. 1A). In addition, the amounts of VEGF expression by $10 \mathrm{nM}$ TPA treatment were increased to $291.7 \%$ and 231.3\% of the control level in MCF7 and T47D breast cancer cells, respectively (Fig. 1B).

Here, we also examined the expression of FN by TPA in MCF7 and T47D breast cancer cells. As shown in Fig. 1C, the levels of FN expression were increased by TPA treatment in a dose-dependent manner. In both cell culture media and whole cell lysates, the expression of FN protein was increased in MCF7 and T47D breast cancer cells (Fig. 1C). Recently, we reported that the level of MMP-1 expression was increased by TPA in breast cancer cells [8]. So, we confirmed as positive control that the MMP-1 protein expression was increased by TPA treatment in cell culture media (Fig. 1C).

TPA-induced VEGF and FN expressions are regulated through PI-3K/Akt dependent pathway in MCF7 breast cancer cells

To investigate the regulatory mechanism of TPA-induced VEGF and FN expression, we pretreated MCF7 cells with specific inhibitors such as LY, PI-3K inhibitor, UO, MEK1/2 inhibitor, and Go, PKC inhibitor, respectively, for $30 \mathrm{~min}$ prior to the $10 \mathrm{nM}$ TPA treatment. We found that TPA-induced VEGF secretion was decreased by in all inhibitors (Fig. 2A). The levels of VEGF secretion was increased to $323.0 \%$ of the control level by $10 \mathrm{nM}$ TPA treatment (Fig. 2A). On the other hand, TPA-induced VEGF secretion was significantly decreased by $150.5 \%, 162.7 \%, 137.1 \%$, and $93.2 \%$ of the control level by $10 \mu \mathrm{M} \mathrm{LY}, 10 \mu \mathrm{M}$ AKT IV, 10 $\mu \mathrm{M}$ UO, and $10 \mu \mathrm{M}$ Go treatment, respectively (Fig. 2A). However, TPA-induced FN protein and mRNA expression was decreased by LY, PI-3K inhibitor (Fig. 2B) but not by UO or Go (data not shown). We also verified that TPA-induced FN protein and mRNA expression was 
Fig. 1. TPA augments the levels of VEGF and fibronectin expression in MCF7 and T47D breast cancer cells. (A) After serum-starvation for $24 \mathrm{~h}$, the MCF7 cells were treated with $10 \mathrm{nM}$ TPA for the indicated times. (B) After serum-starvation for $24 \mathrm{~h}$, the MCF7 and T47D cells were treated with TPA at the indicated doses for $24 \mathrm{~h}$. The levels of secreted VEGF protein were analyzed by ELISA. (C)

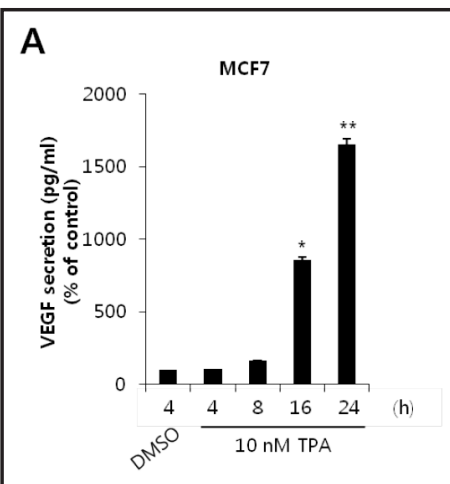

\section{B}

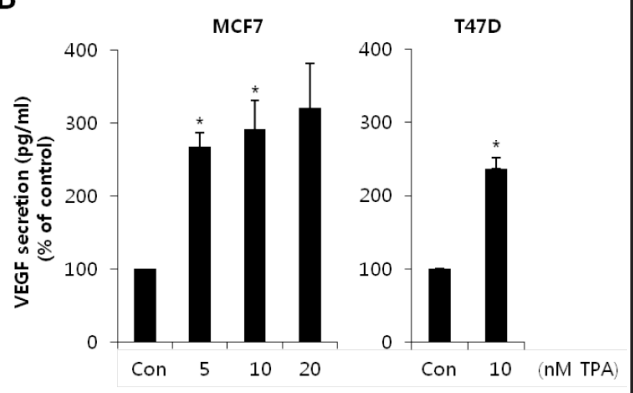

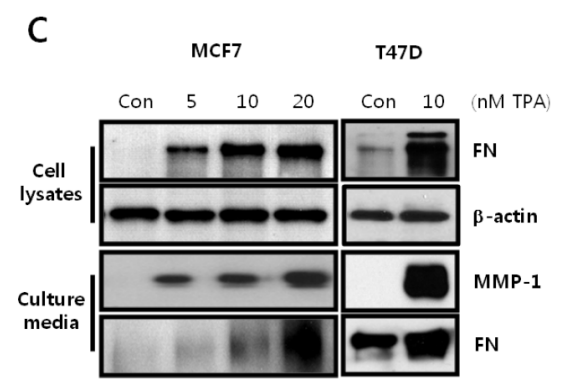

After serum-starvation for $24 \mathrm{~h}$, the MCF7 and T47D cells were treated with TPA at the indicated doses for $24 \mathrm{~h}$. The levels of fibronectin, MMP-1 and $\beta$-actin protein expression were analyzed by western blotting. The results are representative of three independent experiments. The values shown are the means \pm SEM. * $P<0.05$ or ${ }^{* *} P<0.01$ vs. control. Con: control.

decreased by Akt IV inhibitor, Akt inhibitor which is a downstream signaling molecule of PI3K (Fig. 2B).

In addition, we investigated the effect of constitutively active (CA)-PKC, MEK, and AKT overexpression in MCF7 breast cancer cells. As expected, our results showed that the levels of FN protein expression were significantly increased by CA-AKT overexpression but not by CA-PKC $\alpha$, CA-MEK, or dominant negative (DN)-AKT overexpression (Fig. 2C).

We investigated the effect of FN protein and mRNA expression by TPA-induced VEGF in MCF7 breast cancer cells. As shown in Fig. 2D, TPA-induced FN protein and mRNA expression was significantly decreased by VEGFR inhibitor, Tivozanib.

Based on these results, we demonstrated that TPA-induced VEGF and FN expressions are regulated through a PI-3K/Akt dependent pathway. In addition, TPA-induced VEGF affect the level of FN expression in breast cancer cells.

TPA-induced VEGF and FN expressions are suppressed by berberine (BBR) treatment

We investigated whether BBR is involved with the TPA-induced VEGF and FN expressions. The chemical structure of BBR represented in Fig. 3A. As shown in Fig. 3B, the cell viabilities of MCF7 and T47D breast cancer cells were not affected by BBR treatment at the indicated doses. So, we chose the $100 \mu \mathrm{M}$ BBR concentration for further study.

Next, we treated the cells with $10 \mathrm{nM}$ TPA for $24 \mathrm{~h}$ after pretreatment with BBR for $60 \mathrm{~min}$. To assess the levels of VEGF and FN protein and mRNA expression, we harvested the cell lysates and culture media, respectively. Our results showed that the induction of VEGF secretion by TPA was significantly decreased by BBR treatment in MCF7 and T47D breast cancer cells (Fig. 4A). The levels of TPA-induced VEGF expression was suppressed by $126.3 \%$ and $33.1 \%$ of the control level by $100 \mu \mathrm{M}$ BBR treatment, respectively (Fig. 4A). Under the same conditions, we investigated the effect of BBR on TPA-induced FN protein and 
Fig. 2. TPA-induced fibronectin expression is regulated through the PI3K/ Akt dependent pathway. (A) After serum-starvation for $24 \mathrm{~h}$, the MCF7 cells were pretreated with 10 $\mu \mathrm{M}$ LY, AKT IV, U, and Go, respectively, for $30 \mathrm{~min}$, and then they were treated with 10 nM TPA for 24 $h$. The levels of the secreted VEGF protein were analyzed by ELISA. (B) After serum-starvation for $24 \mathrm{~h}$, the MCF7 cells were pretreated with $10 \mu \mathrm{M}$ LY and Akt IV, respectively, for $30 \mathrm{~min}$, and then they were treated with $10 \mathrm{nM}$ TPA for 24 h. (C) After the MCF7 cells were pCMV6 (control) or myr-PKC- $\alpha$ $(0.4 \mu \mathrm{g})$ plasmid DNA transfected for $48 \mathrm{~h}$, respectively, they were then serum-starved for $24 \mathrm{~h}$ (left). After adenoviral CAMEK (middle), DN-AKT, or CA-AKT (right) transfection for $24 \mathrm{~h}$, respectively, the cells were further incubated in serum-free media for 24 h. (D) After serum-starvation for $24 \mathrm{~h}$,

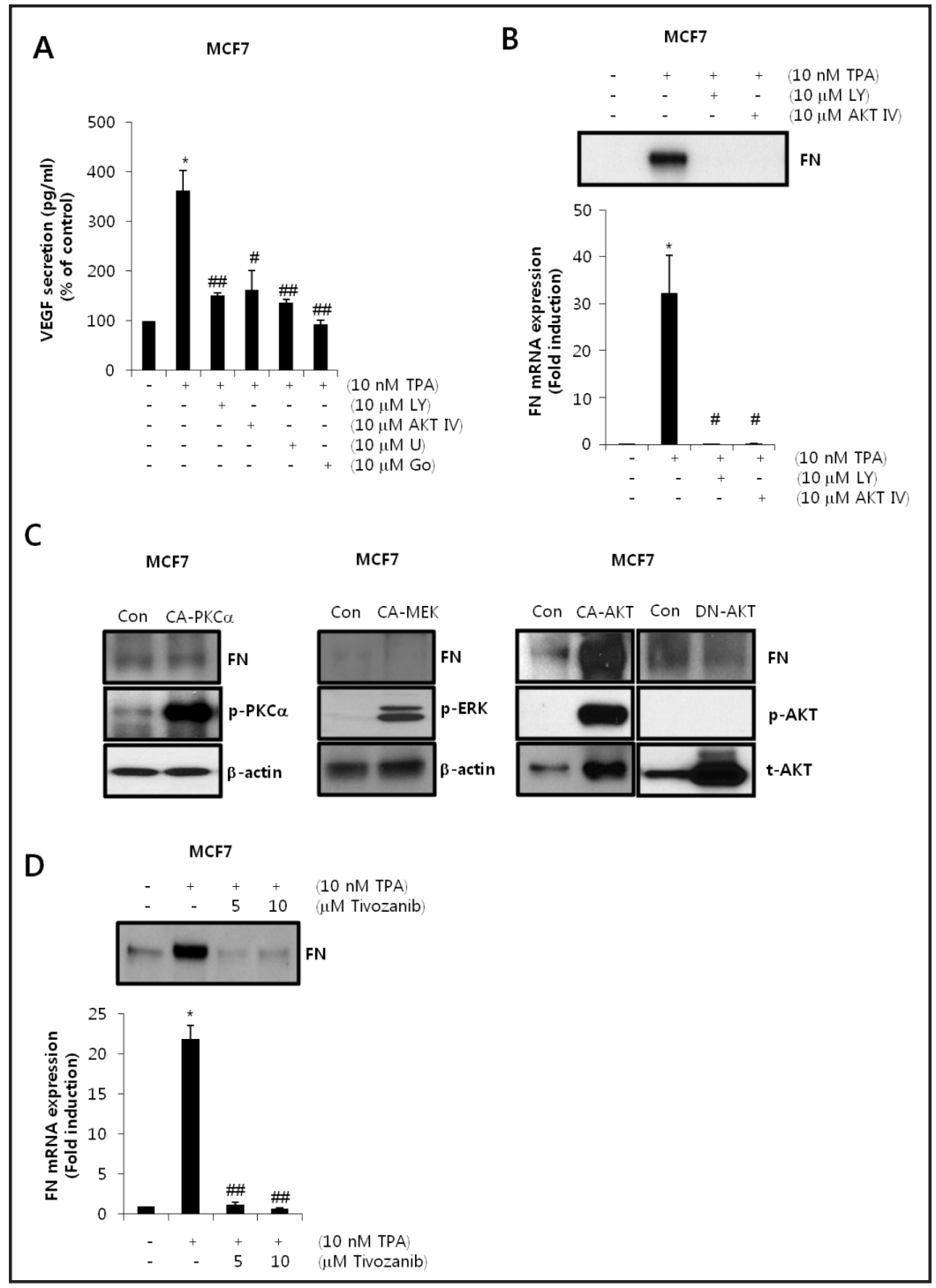
the MCF7 cells were co-treated with $10 \mathrm{nM}$ TPA and the indicated doses VEGFR inhibitor, Tivozanib, for 24 $h$. The levels of fibronectin, p-PKC- $\alpha$, p-ERK, p-AKT, t-AKT and $\beta$-actin protein expression were analyzed by western blotting. The levels of fibronectin mRNA were analyzed by real-time PCR. The results are representative of three independent experiments. The values shown are the means \pm SEM. ${ }^{*} P<0.05,{ }^{* *} P<0.01$ vs. control. \# P<0.05, \#\# P<0.01 vs. TPA-treated cells. Con: control. LY: LY294002, U: U0126, Go: Go6983, Akt IV: Akt IV inhibitor.

mRNA expression. As expected, our results showed that the up-regulation of FN expression in response to TPA was decreased by BBR treatment in MCF7 and T47D breast cancer cells (Fig. 4B).

VEGF-induced FN expression is suppressed by BBR treatment in breast cancer cells

We investigated whether VEGF regulates the level of FN expression in breast cancer cells. The cells were treated with VEGF at the indicated concentration for $24 \mathrm{~h}$. To assess the levels of FN protein expression, we harvested the cell culture media. As shown in Fig. 5A, the basal level of FN protein expression was significantly increased by VEGF treatment in MCF7 and T47D breast cancer cells. 
A

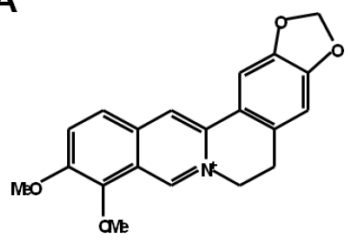

B

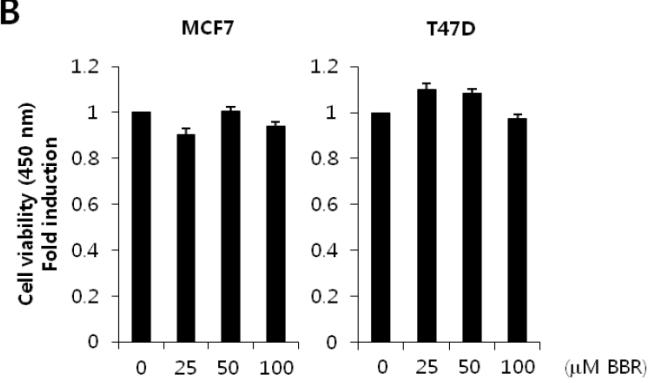

Fig. 3. The effect of berberine on cell viability. (A) The chemical structure of berberine. (B) After serum starvation for $24 \mathrm{~h}$, MCF7 and T47D cells were treated with berberine at the indicated concentration for 24 h. The viabilities of the cells were analyzed by an MTT assay, as described in Materials and Methods. These results are representative of three independent experiments.

Fig. 4. TPA-induced VEGF and fibronectin expressions are suppressed by berberine treatment. (A) After serum-starvation for $24 \mathrm{~h}$, MCF7 and T47D cells were pretreated with 50 and $100 \mu \mathrm{M}$ berberine, respectively, for $60 \mathrm{~min}$ and then they were treated with $10 \mathrm{nM}$ TPA for $24 \mathrm{~h}$. The levels of secreted VEGF protein were analyzed by ELISA. (B) Under the same conditions, the levels of fibronectin protein and mRNA expression were analyzed by western blotting and real-time PCR, respectively. The results are representative of three independent experiments. The values shown are the means \pm SEM. ${ }^{*} P<$ 0.05 , ** $P<0.01$ vs. control. \# $P<0.05$, \#\# $P<0.01$ vs. TPA-treated cells. Con: control.
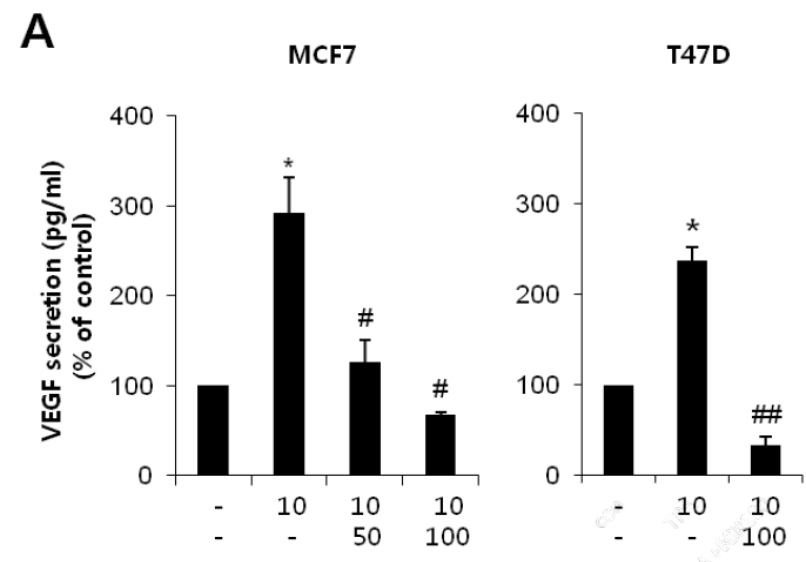

(nM TPA)

B

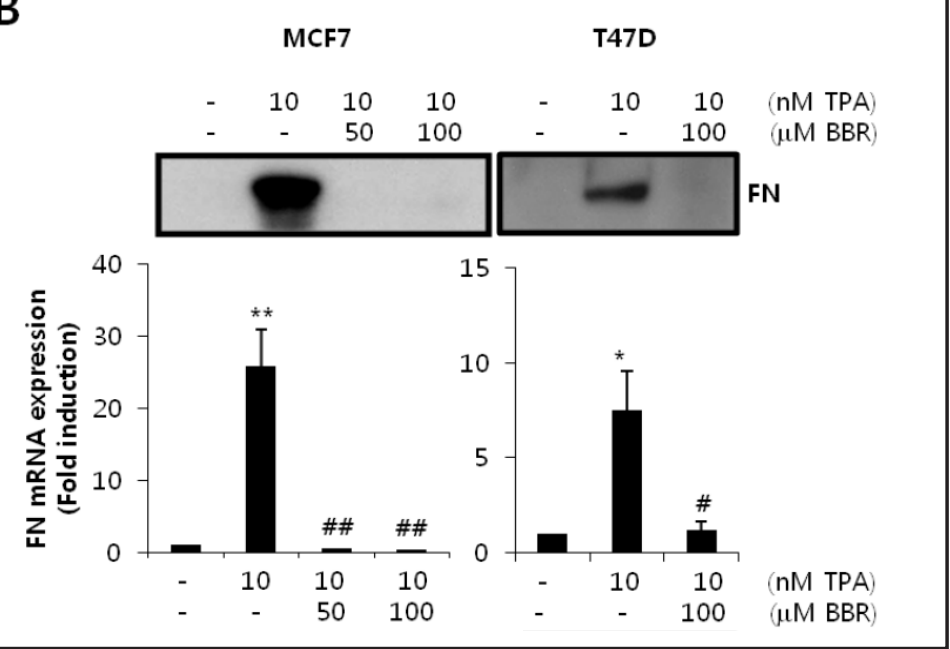

Finally, we studied the effect of BBR on the VEGF-induced FN expression in MCF7 and T47D breast cancer cells. After pretreatment with 50 and $100 \mu \mathrm{M}$ BBR for $60 \mathrm{~min}$, the cells were treated with $10 \mathrm{nM}$ TPA for $24 \mathrm{~h}$. Here, we observed that VEGF-induced FN expression was decreased by BBR treatment (Fig. 5B). Therefore, we demonstrated that BBR may suppress VEGF-induced FN expression, and that this is regulated through the inhibition of the PI-3K/AKT dependent pathway in breast cancer cells. 
A
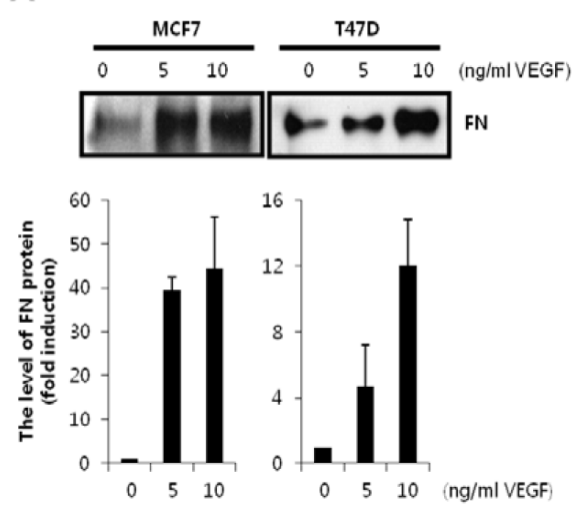

B
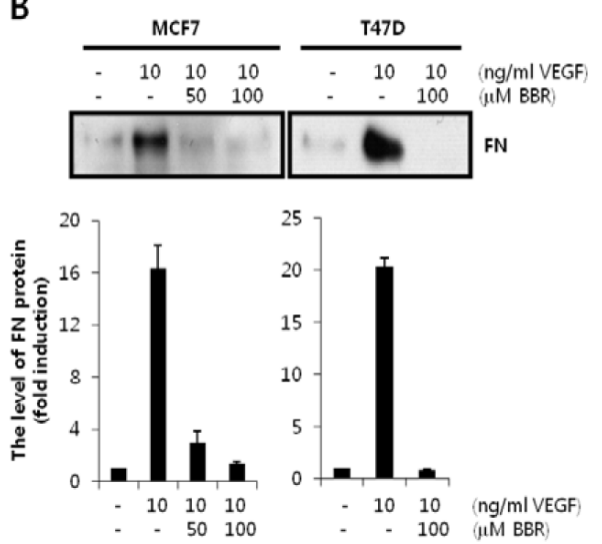

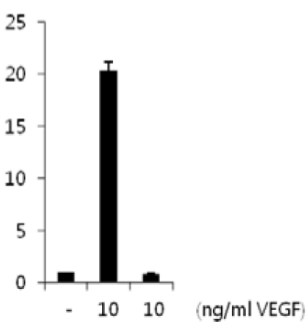

Fig. 5. VEGF-induced fibronectin is suppressed by berberine treatment. (A) After serum-starvation for 24 $\mathrm{h}$, the MCF7 and T47D cells were treated with VEGF at the indicated doses for $24 \mathrm{~h}$. (B) After serum-starvation for $24 \mathrm{~h}$, the MCF7 and T47D cells were pretreated with 50 and $100 \mu \mathrm{M}$ berberine, respectively, for 60 min and then they were treated with $10 \mathrm{ng} / \mathrm{ml}$ VEGF for $24 \mathrm{~h}$. The levels of fibronectin protein expression were analyzed in the culture media by western blotting. The results are representative of three independent experiments. Con: control.

\section{Discussion}

Phorbol esters such as TPA are natural molecules that are well known potent tumor promoters [25]. The phorbol esters play a key role in the activation of PKC, which triggers various cellular responses including inflammation, cell proliferation, and cell differentiation $[26,27]$. In a recent study, we reported that TPA augments the secretion of VEGF protein through Raf/MEK/ERK pathway in breast cancer cells [28]. In this study, we found that the levels of fibronectin (FN) mRNA and protein expression significantly became increased by TPA treatment. Here, we investigated the inhibitory effect of BBR on TPA-induced VEGF and VEGF-induced FN expression in breast cancer cells.

VEGF serves as a key angiogenic factor in a wide range of human cancers $[29,30]$ and has a pivotal role in the metastasis of solid tumors [31]. VEGF and its receptors are frequently overexpressed in human tumors such as breast, colorectal and prostate cancers [30, 32, 33]. In addition, transcriptional activity of VEGF is regulated by its many transcriptional activators, including Sp1, HIF-1, AP-2 and STAT3 [34-36]. TPA also significantly increases the transcriptional activity of Sp1 in the human hepatocarcinoma cell line HepG2 [37]. We found that the levels of VEGF expression significantly were increased by TPA treatment. On the other hand, TPA-induced VEGF expression was completely inhibited by phosphatidylinositol 3-kinase (PI3K) inhibitor, MEK1/2 inhibitor, and PKC inhibitor, respectively. Therefore, we suggest that these signaling pathways indirectly or directly play an important role on the regulation of TPA-induced VEGF expression in breast cancer cells.

FN is an adhesive glycoprotein and is highly expressed in the stroma of breast tumors than in normal adult breast tissue [38]. FN is associated with motility and migration [39]. FN-stimulated cell migration and invasion is achieved through the activation of FAK, which regulates MMP-9 through ERK1/2 signaling in non-small cell lung carcinoma [39].

VEGF/VEGFR complex activates downstream signaling pathways, including the PI3K/ Akt and the Raf/MEK/ERK pathways and then controls the cell proliferation and migration [40]. Kazi et al. reported that VEGF-bounded VEGF receptor, flt-1 induces FN secretion through an ERK dependent pathway in human airway smooth muscle cells [41]. However, our results showed that the expression of FN is mediated by a PI3K/Akt dependent pathway in breast cancer cells. In addition, the levels of FN expression were significantly increased in CA-Akt overexpresed cells. Therefore, we demonstrate that the PI3K/Akt pathway plays an important role in TPA- and VEGF-induced FN expression. 
In conclusion, we found that TPA significantly augments the levels of VEGF and FN expression through the PI3K/AKT dependent pathway in breast cancer cells. Surprisingly, TPA-induced VEGF and FN expressions as well as VEGF-induced FN are inhibited by BBR. Therefore, we have demonstrated that BBR may be used as a candidate drug to produce anti-angiogenic and anti-EMT effects in human breast cancer through the suppression of the VEGF expressions.

\section{Acknowledgements}

This works was supported by a Korea Research Foundation Grant funded by the Korean Government (NRF-2012R1A1B4000493) and in part by Samsung Biomedical Research Institute grant [GL1B31311].

\section{References}

1 Harris JR, Lippman ME, Veronesi U, Willett W: Breast cancer (1). N Engl J Med 1992;327:319-328.

-2 Rabbani SA, Mazar AP: Evaluating distant metastases in breast cancer: From biology to outcomes. Cancer Metastasis Rev 2007;26:663-674.

3 Kalluri R, Weinberg RA: The basics of epithelial-mesenchymal transition. J Clin Invest 2009;119:14201428.

-4 Zeisberg M, Neilson EG: Biomarkers for epithelial-mesenchymal transitions. J Clin Invest 2009;119:14291437.

5 Ikram M: A review on the chemical and pharmacological aspects of genus berberis. Planta Med 1975;28:353-358.

6 Liu Z, Liu Q, Xu B, Wu J, Guo C, Zhu F, Yang Q, Gao G, Gong Y, Shao C: Berberine induces p53-dependent cell cycle arrest and apoptosis of human osteosarcoma cells by inflicting DNA damage. Mutat Res 2009;662:7583.

7 Kim JB, Lee KM, Ko E, Han W, Lee JE, Shin I, Bae JY, Kim S, Noh DY: Berberine inhibits growth of the breast cancer cell lines mcf-7 and mda-mb-231. Planta Med 2008;74:39-42.

-8 Kim S, Han J, Lee SK, Choi MY, Kim J, Lee J, Jung SP, Kim JS, Kim JH, Choe JH, Lee JE, Nam SJ: Berberine suppresses the tpa-induced mmp-1 and mmp-9 expressions through the inhibition of pkc-alpha in breast cancer cells. J Surg Res 2012;176:e21-29.

-9 Lin JP, Yang JS, Wu CC, Lin SS, Hsieh WT, Lin ML, Yu FS, Yu CS, Chen GW, Chang YH, Chung JG: Berberine induced down-regulation of matrix metalloproteinase-1, -2 and -9 in human gastric cancer cells (snu-5) in vitro. In Vivo 2008;22:223-230.

10 Kim S, Choi JH, Kim JB, Nam SJ, Yang JH, Kim JH, Lee JE: Berberine suppresses tnf-alpha-induced mmp-9 and cell invasion through inhibition of ap-1 activity in mda-mb-231 human breast cancer cells. Molecules 2008;13:2975-2985.

11 Carmeliet P, Jain RK: Angiogenesis in cancer and other diseases. Nature 2000;407:249-257.

12 Folkman J: What is the evidence that tumors are angiogenesis dependent? J Natl Cancer Inst 1990;82:4-6.

13 Ferrara N: Vascular endothelial growth factor as a target for anticancer therapy. Oncologist 2004;9 Suppl 1:2-10.

14 Ferrara N, Houck K, Jakeman L, Leung DW: Molecular and biological properties of the vascular endothelial growth factor family of proteins. Endocr Rev 1992;13:18-32.

15 Hicklin DJ, Ellis LM: Role of the vascular endothelial growth factor pathway in tumor growth and angiogenesis. J Clin Oncol 2005;23:1011-1027.

16 Relf M, LeJeune S, Scott PA, Fox S, Smith K, Leek R, Moghaddam A, Whitehouse R, Bicknell R, Harris AL: Expression of the angiogenic factors vascular endothelial cell growth factor, acidic and basic fibroblast growth factor, tumor growth factor beta-1, platelet-derived endothelial cell growth factor, placenta growth factor, and pleiotrophin in human primary breast cancer and its relation to angiogenesis. Cancer Res 1997;57:963-969.

17 Price DJ, Miralem T, Jiang S, Steinberg R, Avraham H: Role of vascular endothelial growth factor in the stimulation of cellular invasion and signaling of breast cancer cells. Cell Growth Differ 2001;12:129-135.

18 Hsiong SX, Huebsch N, Fischbach C, Kong HJ, Mooney DJ: Integrin-adhesion ligand bond formation of preosteoblasts and stem cells in three-dimensional rgd presenting matrices. Biomacromolecules 2008;9:1843-1851. 
Kim et al.: The effect of Berberine on VEGF and Fibronectin Expression

19 Mantovani A, Allavena P, Sica A, Balkwill F: Cancer-related inflammation. Nature 2008;454:436-444.

20 Chao YL, Shepard CR, Wells A: Breast carcinoma cells re-express e-cadherin during mesenchymal to epithelial reverting transition. Mol Cancer 2010;9:179.

21 Christensen L: The distribution of fibronectin, laminin and tetranectin in human breast cancer with special attention to the extracellular matrix. APMIS Suppl 1992;26:1-39.

-22 Hodges RR, Kazlauskas A, Toker A, Dartt DA: Effect of overexpression of protein kinase c alpha on rat lacrimal gland protein secretion. Adv Exp Med Biol 2002;506:237-241.

-23 Shimao Y, Nabeshima K, Inoue T, Koono M: Tpa-enhanced motility and invasion in a highly metastatic variant (1-10) of human rectal adenocarcinoma cell line rcm-1: Selective role of pkc-alpha and its inhibition by a combination of pdbu-induced pkc downregulation and antisense oligonucleotides treatment. Clin Exp Metastasis 1999;17:351-360.

-24 Schlingemann J, Hess J, Wrobel G, Breitenbach U, Gebhardt C, Steinlein P, Kramer H, Furstenberger G, Hahn M, Angel P, Lichter P: Profile of gene expression induced by the tumour promotor tpa in murine epithelial cells. Int J Cancer 2003;104:699-708.

25 Segal A, Van Duuren BL, Mate U: The identification of phorbolol myristate acetate as a new metabolite of phorbol myristate acetate in mouse skin. Cancer Res 1975;35:2154-2159.

-26 Silinsky EM, Searl TJ: Phorbol esters and neurotransmitter release: More than just protein kinase c? Br J Pharmacol 2003;138:1191-1201.

27 Clemens MJ, Trayner I, Menaya J: The role of protein kinase c isoenzymes in the regulation of cell proliferation and differentiation. J Cell Sci 1992;103:881-887.

28 Kim S, Choi JH, Lim HI, Lee SK, Kim WW, Kim JS, Kim JH, Choe JH, Yang JH, Nam SJ, Lee JE: Silibinin prevents tpa-induced mmp-9 expression and vegf secretion by inactivation of the raf/mek/erk pathway in mcf-7 human breast cancer cells. Phytomedicine 2009;16:573-580.

29 Jain L, Vargo CA, Danesi R, Sissung TM, Price DK, Venzon D, Venitz J, Figg WD: The role of vascular endothelial growth factor snps as predictive and prognostic markers for major solid tumors. Mol Cancer Ther 2009;8:2496-2508.

-30 Yoshiji H, Gomez DE, Shibuya M, Thorgeirsson UP: Expression of vascular endothelial growth factor, its receptor, and other angiogenic factors in human breast cancer. Cancer Res 1996;56:2013-2016.

31 Makrilia N, Lappa T, Xyla V, Nikolaidis I, Syrigos K: The role of angiogenesis in solid tumours: An overview. Eur J Intern Med 2009;20:663-671.

-32 Ferrer FA, Miller LJ, Andrawis RI, Kurtzman SH, Albertsen PC, Laudone VP, Kreutzer DL: Angiogenesis and prostate cancer: In vivo and in vitro expression of angiogenesis factors by prostate cancer cells. Urology 1998;51:161-167.

-33 Yamaguchi T, Bando H, Mori T, Takahashi K, Matsumoto H, Yasutome M, Weich H, Toi M: Overexpression of soluble vascular endothelial growth factor receptor 1 in colorectal cancer: Association with progression and prognosis. Cancer Sci 2007; 98:405-410.

-34 Loureiro RM, D'Amore PA: Transcriptional regulation of vascular endothelial growth factor in cancer. Cytokine Growth Factor Rev 2005;16:77-89.

35 Abdelrahim M, Smith R 3 ${ }^{\text {rd }}$, Burghardt R, Safe S: Role of sp proteins in regulation of vascular endothelial growth factor expression and proliferation of pancreatic cancer cells. Cancer Res 2004;64:6740-6749.

-36 Gille J, Swerlick RA, Caughman SW: Transforming growth factor-alpha-induced transcriptional activation of the vascular permeability factor (vpf/vegf) gene requires ap-2-dependent DNA binding and transactivation. EMBO J 1997;16:750-759.

-37 Porntadavity S, Xu Y, Kiningham K, Rangnekar VM, Prachayasittikul V, St Clair DK: Tpa-activated transcription of the human mnsod gene: Role of transcription factors sp-1 and egr-1. DNA Cell Biol 2001;20:473-481.

-38 Helleman J, Jansen MP, Ruigrok-Ritstier K, van Staveren IL, Look MP, Meijer-van Gelder ME, Sieuwerts AM, Klijn JG, Sleijfer S, Foekens JA, Berns EM: Association of an extracellular matrix gene cluster with breast cancer prognosis and endocrine therapy response. Clin Cancer Res 2008;14:5555-5564.

-39 Meng XN, Jin Y, Yu Y, Bai J, Liu GY, Zhu J, Zhao YZ, Wang Z, Chen F, Lee KY, Fu SB: Characterisation of fibronectin-mediated fak signalling pathways in lung cancer cell migration and invasion. Br J Cancer 2009;101:327-334.

40 Lentzsch S, Chatterjee M, Gries M, Bommert K, Gollasch H, Dorken B, Bargou RC: Pi3-k/akt/fkhr and mapk signaling cascades are redundantly stimulated by a variety of cytokines and contribute independently to proliferation and survival of multiple myeloma cells. Leukemia 2004;18:1883-1890.

41 Kazi AS, Lotfi S, Goncharova EA, Tliba O, Amrani Y, Krymskaya VP, Lazaar AL: Vascular endothelial growth factor-induced secretion of fibronectin is erk dependent. Am J Physiol Lung Cell Mol Physiol 2004;286:L539-545. 